\title{
Identification of candidate reference genes in tropical bamboos stable across species, tissues, and developmental stages
}

\author{
S. CHAKRABORTY, S. DUTTA, P. BISWAS, and M. DAS* \\ Department of Life Sciences, Presidency University, 700073 Kolkata, India
}

\begin{abstract}
Bamboo possesses many unique physiological characteristics, but the molecular understanding of many of these processes remains poorly understood till to date. One major reason is unavailability of sufficient sequence and expression data. Selection of suitable reference genes is pivotal to initiate any gene expression analyses. Although, suitable reference genes have been identified in the temperate bamboo Phyllostachys edulis, it has not been done for tropical bamboo. In this study, expression stability of 10 candidate reference genes were investigated in 4 widely grown tropical bamboo species (Bambusa tulda, B. balcooa, B. bambos, and B. vulgaris), different organs (young leaves from flowering and non-flowering culms, flag leaf (leaf just below the mature inflorescence), possible flag leaf (leaf covering the immature inflorescence), culm sheath, internode, root, rhizome, and inflorescence bud), different parts (basal, middle, and tip regions of leaf; internodes located in the basal, middle, and tip region of the branch, and developmental stages early, middle, and late inflorescence buds) by using 3 reliable computational tools (geNorm, NormFinder, and RefFinder). A universal single reference gene for normalization of gene expression data was not identified. However, the eukaryotic initiation factor $4 \alpha$ (eIF4 $\alpha)$, clathirin adaptor complexes medium subunit (CAC), and nucleotide tractbinding protein $(N T B)$ were found stable in the selected organs across different bamboo species. On the other hand, eIF4a ranked top when different organs and peptidyl prolyl cis-trans isomerase/cyclophilin (CYP), eukaryotic elongation factor $1 \alpha(e E F 1 \alpha)$ and ubiquitin 5 (UBQ5) ranked top when different developmental stages of $B$. tulda were analyzed. Taken together, this study not only identifies reference gene/s that are stable across species, organs, and developmental stages of bamboo, but it also assesses the impacts of major contributing factors regulating expression stability of the reference genes.
\end{abstract}

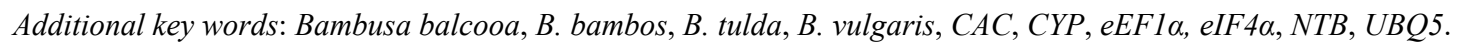

\section{Introduction}

Bamboos are members of the subfamily Bambusoideae, family Poaceae. They are profusely growing in different regions of Asia, America, and Africa (Clark et al. 2015). A well-developed bamboo culm offers a multiple usage, such as in construction purposes, charcoal production, and a raw material for paper and pulp production, whereas young shoots are used as vegetable (Lobovikov et al. 2007, Owen 2015). Research on bamboo has traditionally been restricted to phylogenetic studies (Zhang 2000, Clark et al. 2007, Das et al. 2008), standardization of in vitro regeneration methods (Das and Pal 2005, Ramanayake et al. 2006, Yuan et al. 2017), ecological studies on the unusually long flowering cycle (Janzen 1976, Marchesini et al. 2009, Sertse et al. 2011),

Submitted 25 April 2018, last revision 17 September 2018, accepted 9 October 2018.

Abbreviations: $18 \mathrm{~S}$ - 18S ribosomal RNA; ACT7 - actin 7; CAC - clathirin adaptor complexes medium subunit; CS - culm sheath; CYP - peptidyl prolyl cis-trans isomerase/cyclophilin; E - early staged inflorescence bud; eEF1 $\alpha$ - eukaryotic elongation factor $1 \alpha$; eIF4 $\alpha$ - eukaryotic initiation factor $4 \alpha$; FL - flag leaf; GAPDH - glyceraldehyde-3-phosphate dehydrogenase; I - internode; L - late staged inflorescence bud; M - middle staged inflorescence bud; NTB - nucleotide tract-binding protein; PFL - possible flag leaf; $\mathrm{R}$ - root; RH - rhizome; RPKM - reads per kilobase million;TOC1 - timing of CAB expression1; UBQ - ubiquitin; YLF - young leaf from flowering culm; YLN - young leaf from non-flowering culm.

Acknowledgements: This research was funded by the Council of Scientific and Industrial Research, India [38(1386)/14/EMR-II], the Department of Biotechnology, India (BT/PR10778/PBD/16/1070/2014), and the FRPDF grant of Presidency University. PB acknowledges a Junior Research Fellowship from the University Grant Commission, India. We also thank Prof. Anuradha Lohia and Prof. Amita Pal for their constant encouragements.

* Corresponding author; email: malay.dbs@presiuniv.ac.in 
and fiber extraction processes for the benefit of paper and pulp industry (Wai et al. 1985, Sood et al. 2005). Compared to that, molecular studies are very limited and the only bamboo genome that has been sequenced till to date is the temperate bamboo Phyllostachys edulis (Peng et al. 2013, Biswas et al. 2016). However, in order to harvest the full economic potential of this plant group, molecular studies on Bambusa that hosts approximately 100 species (Kellogg 2015) are very important. In spite of enormous economic potential, one major reason for lack of sufficient molecular studies on Bambusa is the unavailability of sufficient gene sequences and their expression data. The first step towards this effort is the identification of suitable reference genes.

Real time quantitative (q) PCR method is one of the most reliable and commonly used techniques to study expression of a limited number of genes. One major advantage of this technique over large scale analyses, such as microarray or the reads per kilobase million (RPKM) method employed in transcriptome sequencing, is its high accuracy and specificity, which enables it to measure the transcriptional abundance of even lowly expressed genes (Ginzinger 2002, Bustin et al. 2005, Fedick et al. 2012). However, in order to avoid obtaining differential expression due to technical discrepancies, proper data normalization using a set of stable reference genes is mandatory. Therefore, extensive studies have been performed over the years to identify suitable reference genes that are stable across species (Iskandar et al. 2004, Morgante et al. 2011), developmental stages (Jain et al. 2006, Fan et al. 2013, Li et al. 2016), tissues (Jian et al. 2008, Fan et al. 2013, Reddy et al. 2016), different seasons (Kim et al. 2015), and even diverse environmental conditions (Janská et al. 2013, Guo et al. 2014, Silva et al. 2014, De Andrade et al. 2017).

Although standardization of a suitable reference gene has been perfected in the temperate bamboo $P$. edulis (Fan et al. 2013), it is not known yet whether these identified reference genes can be useful for gene expression analyses in the phylogenetically diverged tropical bamboo group (Clark et al. 1995, Gielis et al. 1997). In particular, that study was limited to only six tissues and two developmental stages (Fan et al. 2013). The main objective of this study was to identify suitable reference genes that are stable across species, organs, and developmental stages, and therefore, could be utilized for an accurate normalization of gene expression data for Bambusa. Ten candidate genes were selected for identification of suitable reference genes in bamboo. These genes were previously found effective for normalization in Oryza sativa (Jain et al. 2006), Saccharum officinarum (Ling et al. 2014), P. edulis (Fan et al. 2013), Camellia sinensis (Wang et al. 2017), Sapium sebiferum (Chen et al. 2017), Fortunella crassifolia (Hu et al. 2014,) and Capsicum annuum (Wan et al. 2011).

\section{Materials and methods}

Collection of plant tissues for gene expression analyses: In order to avoid any possible variability due to seasonal effects, plant tissues from eight different organs, three different regions, and four Bambusa species were obtained over a short collection period between May and June in 2017. However, since flowering incidence was rare, flowering tissues of different developmental stages had to be collected over a longer period of time starting from April 2013 to July 2017 from plants located at Shyamnagar $\left(22.83^{\circ} \mathrm{N}, 88.40^{\circ} \mathrm{E}\right)$ and Bandel $\left(22.93^{\circ} \mathrm{N}\right.$, $\left.88.38^{\circ} \mathrm{E}\right)$, West Bengal, India. Three biological replicates for each tissue stage were snap frozen in liquid nitrogen and stored in at $-80{ }^{\circ} \mathrm{C}$. To check the effects of organ variability on the expression stability of the selected reference genes, young leaves from flowering (YLF) and non-flowering (YLN) culms, flag leaves (FL leaf just below the mature inflorescence), possible flag leaves (PFL, leaf covering the immature inflorescence), possible flag leaves (PFL), culm sheaths (CS), internodes (I), roots (R), rhizomes (RH), and early staged inflorescence buds (E) were selected, whereas for analyzing variability due to tissue age, different regions of leaves (basal, middle, and tip), internodes (located in the basal, middle, and tip regions of the branch), and inflorescence buds of varying developmental stages (early, middle, and late) were collected from Bambusa tulda Roxb. In order to assess the impact of species variability, three representative organs (rhizomes, leaves, and internodes) were collected from four widely grown bamboo species $B$. tulda Roxb., B. balcooa Roxb., B. bambos L., and B. vulgaris Schrad. ex Wendl.

Isolation of total RNA and preparation of cDNA libraries: Total RNA was isolated from the selected tissues by using a combination of Trizol (Invitrogen, Carsbad, USA) and RNAeasy plant mini kits (Qiagen, Hilden, Germany; Das et al. 2010, 2016). In order to avoid any genomic DNA contamination, the isolated RNA samples were treated with DNase I (Thermo Fisher Scientific, San Jose, USA). The quality and quantity of RNA was assessed with a BioSpectrometer (Eppendorf, Hamburg, Germany) and agarose $(1 \%, \mathrm{~m} / \mathrm{v})$ formamide gel electrophoresis (Table 1 Suppl., Fig. 1 Suppl.). Approximately $1 \mu \mathrm{g}$ of total RNA was used for first strand cDNA synthesis using a Verso $c D N A$ synthesis kit (Thermo Fisher Scientific) following the manufacturer's protocol, and $2 \mathrm{~mm}^{3}$ of the $1 / 20$ diluted cDNA sample was used for real-time qPCR analyses. 
Primer designing for real-time qPCR analyses: Ten candidate reference genes eukaryotic initiation factor $4 \alpha$

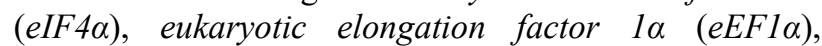
clathirin adaptor complexes medium subunit (CAC), nucleotide tract-binding protein (NTB) peptidyl prolyl cis-trans isomerase/cyclophilin (CYP), ubiquitin 5 (UBQ5), UBQ3, 18S RIBOSOMAL RNA (18S), glyceraldehyde-3-phosphate dehydrogenase (GAPDH), and actin (ACT7) were selected for this study. Homologous sequences of these genes were identified from P. edulis, Oryza sativa, Brachypodium distachyon, Zea mays, Triticum aestivum, and Setaria italica employing the BLASTN program of the PLAZA 4.0 database using a default parameter. These sequences were multiple aligned using the MUSCLE program (https://www.ebi.ac.uk/Tools/msa/muscle/) and primers were designed using the Primer 3 program by targeting the conserved regions (Table 2 Suppl., Fig. 3 Suppl.). For the purpose of the validation of the housekeeping genes, the coding sequences of $B$. tulda MADS14 (KX186751) and TIMING OF CAB EXPRESSION1 (TOC1, KY249524) were obtained to design gene specific primers. In order to avoid amplification from contaminating genomic DNA, if any, primers were designed from either intron flanking or intron spanning regions.

Real-time qPCR analysis was performed using SsoAdvanced Universal SYBR Green Supermix (Bio-Rad, Hercules, USA) in a CFX Connect real-time PCR detection system (Bio Rad). Amplification cycles used were: $95{ }^{\circ} \mathrm{C}$ for $30 \mathrm{~s}, 40$ cycles at $94{ }^{\circ} \mathrm{C}$ for $10 \mathrm{~s}$ and at $55^{\circ} \mathrm{C}$ for 40 s. A dissociation curve analysis was performed at the end of each amplification reaction to confirm the absence of any primer-dimer formation. No template control (NTC) was also included where nuclease free water was used as a template. The efficiency of the qPCR reaction was determined from a standard curve based on 1:5 dilution of cDNA templates using a formula $10^{(-1 / \text { slope) }}-1$ (Ginzinger 2002). In order to investigate the validity of the putative reference genes, relative expressions of BtMADS14 and BtTOC1 were measured in 7 different tissues using the $2^{-\Delta \Delta C t}$ method (Livak and Schmittgen 2001). In this analysis, rhizomes were used as calibrator tissues since they are neutral to flowering, whereas the two tested genes are involved in flower induction and organ differentiation, respectively.

In silico analyses to study the stability of reference genes: To identify the most stable reference genes within the studied experimental sets, three different computational tools were used: geNorm (https:// genorm.cmgg.be/, Vandesompele et al. 2002), NormFinder (https://moma.dk/normfinder-software, Andersen et al. 2004), and comprehensive ranking analysis of RefFinder (http://150.216.56.64/ referencegene.php, Silver et al. 2006). To perform geNorm and NormFinder analyses, the $\mathrm{Ct}$ values were converted to relative quantities by using the $2^{-\mathrm{ACt}}$ method (Vandesompele et al. 2002, Andersen et al. 2004), whereas in the case of RefFinder, the $\mathrm{Ct}$ values were used as input data for further analyses (Silver et al. 2006). To estimate the optimum number of reference genes, pairwise variation analysis in the geNorm program was perfomed by assessing the pairwise variations observed between normalization factors.

\section{Results}

The specificity of the individual primer pairs used for real time qPCR analysis was confirmed by obtaining a single peak in each case when melting curve analysis was performed (Fig. 2 Suppl.). This was reaffirmed by observing single amplified bands in agarose gel electrophoresis (Fig. 4 Suppl.). The estimated PCR efficiency of the primers ranged from 89 to $109 \%$ (Table 2 Suppl.). The mean $\mathrm{Ct}$ values of all the reference genes studied under diverse experimental settings varied (Table 2 Suppl.). The highest $\mathrm{Ct}$ value was observed for $A C T 7$ $(29.55 \pm 0.03)$, while the lowest one found was $U B Q 3$ $(16.14 \pm 0.24$, Fig. 1). In terms of the observed variations among $\mathrm{Ct}$ values of a particular gene under different experimental settings, the lowest variation was observed for $C A C$ and $18 S$, whereas it was highest in GAPDH and eIF $4 \alpha$.

Four members of the genus Bambusa were selected to study the impact of species variability on the expression stability of the candidate reference genes. Tissues were collected from three different organs (young leaf,

internode, and rhizome) from each of the four species. In order to understand the effect of species only, data from each tissue were separately compared among species so that other factors, such as organ or developmental stage, may not cofound the interpretation. The obtained expression data were analyzed in geNorm, NormFinder, and RefFinder.

Out of 10 candidate reference genes, the lowest $\mathrm{M}$ value in geNorm analysis (0.21) was obtained for $e I F 4 \alpha$ and $U B Q 3$ when stability of the reference genes was studied in young leaf tissue across 4 different species (Fig. 2A), whereas $C A C$ was predicted as the most stable gene by NormFinder and RefFinder (Table 3 Suppl.). Similarly, $C A C$ was found most stable by these two tools for internode tissue, whereas in geNorm analysis, these were $e E F 1 \alpha$ and $e I F 4 \alpha$ (Fig. $2 B$ ). However, when data from rhizome tissue were compared across species, NTB was predicted as the most stable reference gene in all three computational tools (Fig. 2C, Table 3 Suppl.).

The expression of a gene may significantly vary 


\section{S. CHAKRABORTY et al.}

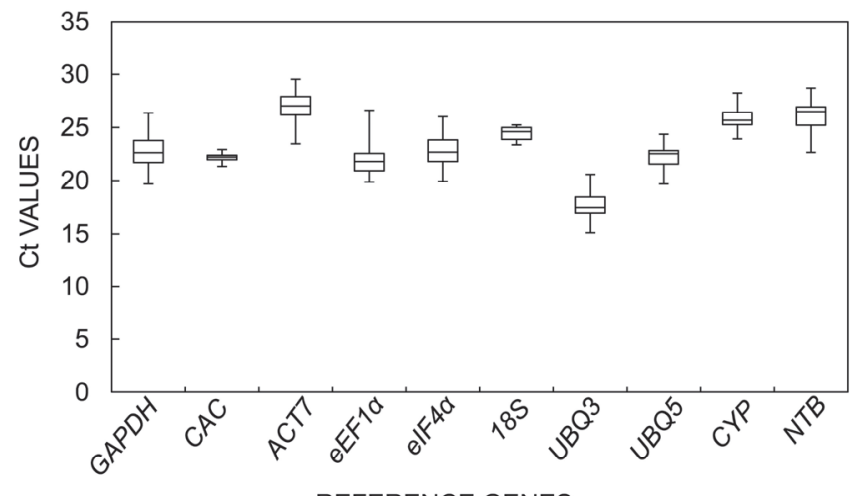

Fig. 1. The Ct values obtained from different developmental stages, organs, and species of Bambusa. The $25^{\text {th }}$ and $75^{\text {th }}$ percentile are indicated in each box. The median is depicted by the straight line crossing the box. The whisker caps represent maximum and minimum values. eEFl $\alpha$ - eukaryotic elongation factor $1 \alpha$, eIF $4 \alpha$ - eukaryotic initiation factor $4 \alpha$, NTB - nucleotide tract-binding protein, CAC - clathirin adaptor complexes medium subunit, CYP - peptidyl prolyl cis-trans isomerase/cyclophilin, $18 S$ - $18 S$ ribosomal RNA, UBQ3 - ubiquitin 3, ACT7-actin 7, GAPDH - glyceraldehyde-3-phosphate dehydrogenase, and UBQ5 - ubiquitin 5.
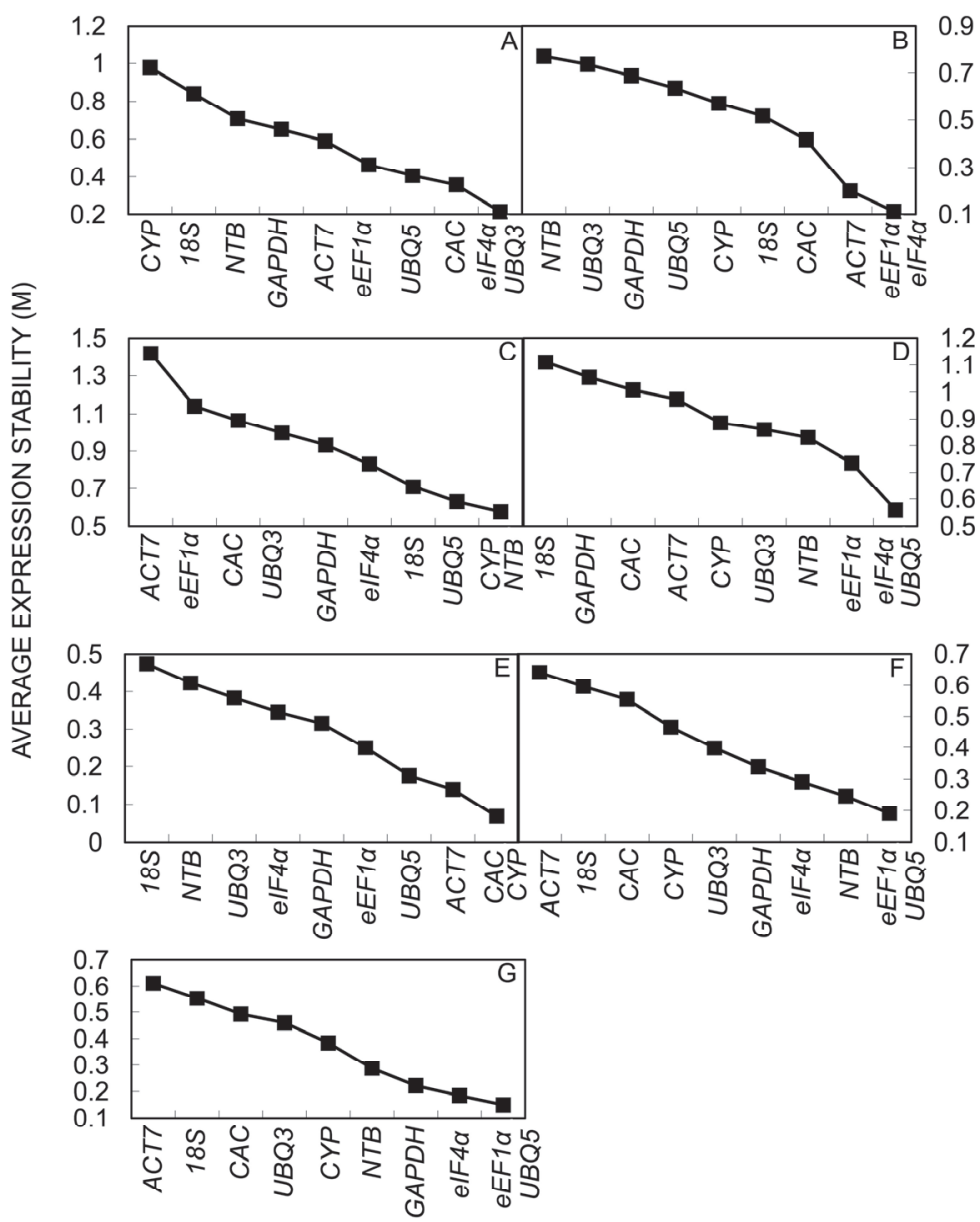

Fig. 2. Gene expression stability and ranking 10 selected candidate reference genes as predicted by geNorm analyses. The $\mathrm{M}$ value refers to average expression stability and the lower $\mathrm{M}$ value signifies a higher stability of expression. The least stable reference genes are on the left and the most stable reference genes are on the right. Leaf tissue across different species $(A)$, internode tissue across different species $(B)$, rhizome tissue across different species $(C)$, nine different tissues from six different organs $(D)$, three regions of leaf $(E)$, internodes collected from top, middle, and base of a branch $(F)$, three developmental stages of inflorescence buds (early, middle, and late) $(G)$. 
across plant organs. In order to understand the influence of organ variability on the expression stability of candidate reference genes, the expression data were assessed in nine tissue samples of $B$. tulda. Out of the 10 candidate reference genes investigated, $U B Q 5$ and $e I F 4 \alpha$ were identified as ideal reference genes in geNorm analysis having the lowest $\mathrm{M}$ value 0.55 (Fig. $2 D$ ). The
NormFinder and RefFinder analyses also predicted eIF $4 \alpha$ as the most stable reference gene having a stability value of 0.545 and 1.41 , respectively (Table 3 Suppl.). However, disagreements among computational tools were noticed in terms of the predicted least stable gene. The $18 S$ was found to be least stable in NormFinder and geNorm analyses, whereas it was GAPDH in RefFinder.

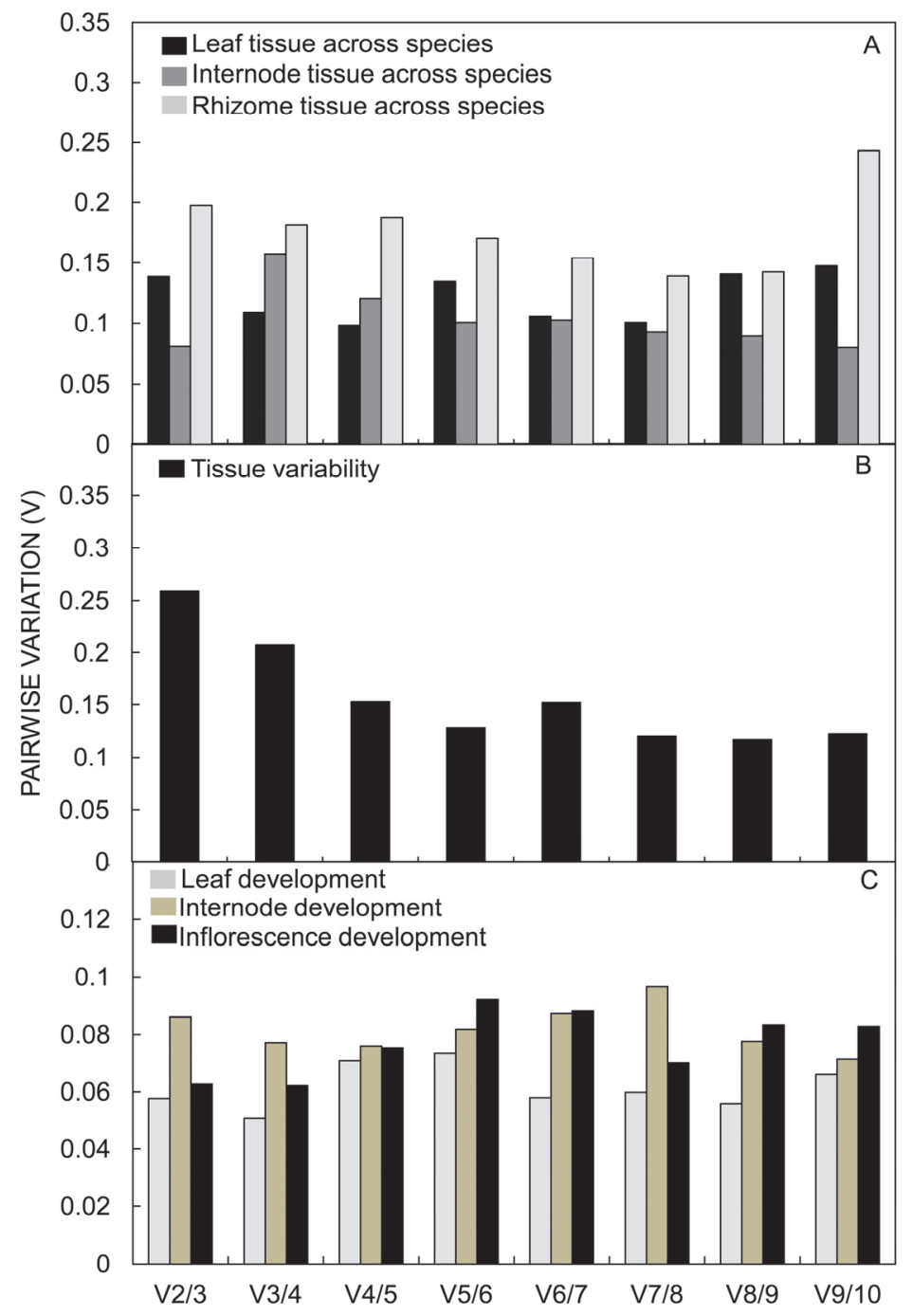

Fig. 3. Estimation of the optimum number of reference genes necessary for normalization of gene expression data. The geNorm software calculated a pairwise variation $(\mathrm{Vn} / \mathrm{n}+1)$ between normalization factors $(\mathrm{NFn}$ and $\mathrm{NFn}+1)$. The pairwise variation value $<$ 0.15 suggests that addition of one more reference gene was not necessary for normalization of gene expression data. Leaf, internode, and rhizome tissues across species $(A)$, nine different tissues from six different organs $(B)$, and three developmental regions of leaf, internode, and three developmental stages of inflorescence bud $(C)$.

In order to study the effects of developmental stages on the expression stability of the studied reference genes, B. tulda tissues were obtained from basal, middle, and tip regions of leaf and also from internodes located in lower, middle, and upper parts of a branch, as well as from early, middle, and late stages of inflorescence buds. When the developmental stages of leaf and internode were considered, the predictions made by NormFinder and RefFinder overlapped. For different regions of leaf, $A C T 7$ was predicted as the most stable reference gene (Table 3 Suppl.). On the contrary, $C A C$ and $C Y P$ were the best reference genes identified in geNorm (Fig. 2E). Similarly, for different regions of internode, eIF $4 \alpha$ was identified as the most stable reference gene by 


\section{S. CHAKRABORTY et al.}

NormFinder (a stability value of 0.143 ) and RefFinder (a stability value of 2.00, Table 3 Suppl.) analyses, which was contradicted by the geNorm analysis suggesting $e E F 1 \alpha$ and $C Y P$ as the most stable ones (an M value of 0.190 , Fig. $2 F$ ). When inflorescence buds of three different developmental stages were analyzed, both geNorm and RefFinder predicted UBQ5 as a suitable reference gene (Fig. $2 G$, Table 3 Suppl.), but it was $C Y P$ in NormFinder analysis (Table 3 Suppl.).

The pairwise variation analysis in the geNorm program was used to estimate the optimum number of reference genes that can be used for data normalization. A pairwise variation value $>0.15$ indicates that addition of another gene is necessary for data normalization. This analysis suggests that use of two genes were sufficient for normalization of data in the case of young leaves and internodes across the selected bamboo species and also across three developmental tissue stages of $B$. tulda (Fig. 3). However, more than three genes were necessary for rhizome tissue across species and also across selected organs of B. tulda.

To confirm the suitability of the identified reference genes for normalization of gene expression data, tissue specific expression patterns of a flower inductive circadian clock gene BtTOC1 and a floral organ identity gene BtMADS14 were analyzed in seven different tissues of $B$. tulda. Expression data of these two genes were normalized using the two most stable (eIF4 $\alpha$ and UBQ5) and one least stable (18S) reference genes (Fig. 4). When normalization was performed using $e I F 4 \alpha$ and $U B Q 5$, the transcript abundance of both these genes was higher in young leaves collected from the flowering culm (YLF) than in young leaves from the non-flowering culm (YLN). This is in line with their established involvement in flower induction (Fig. 4A,B). However, when data were normalized using the predicted least stable reference gene $18 S$, the gene expression of BtTOC1 was higher in YLN than in YLF, whereas no difference in expression between YLF and YLN could be observed in the case of BtMADS14 (Fig. 4C).

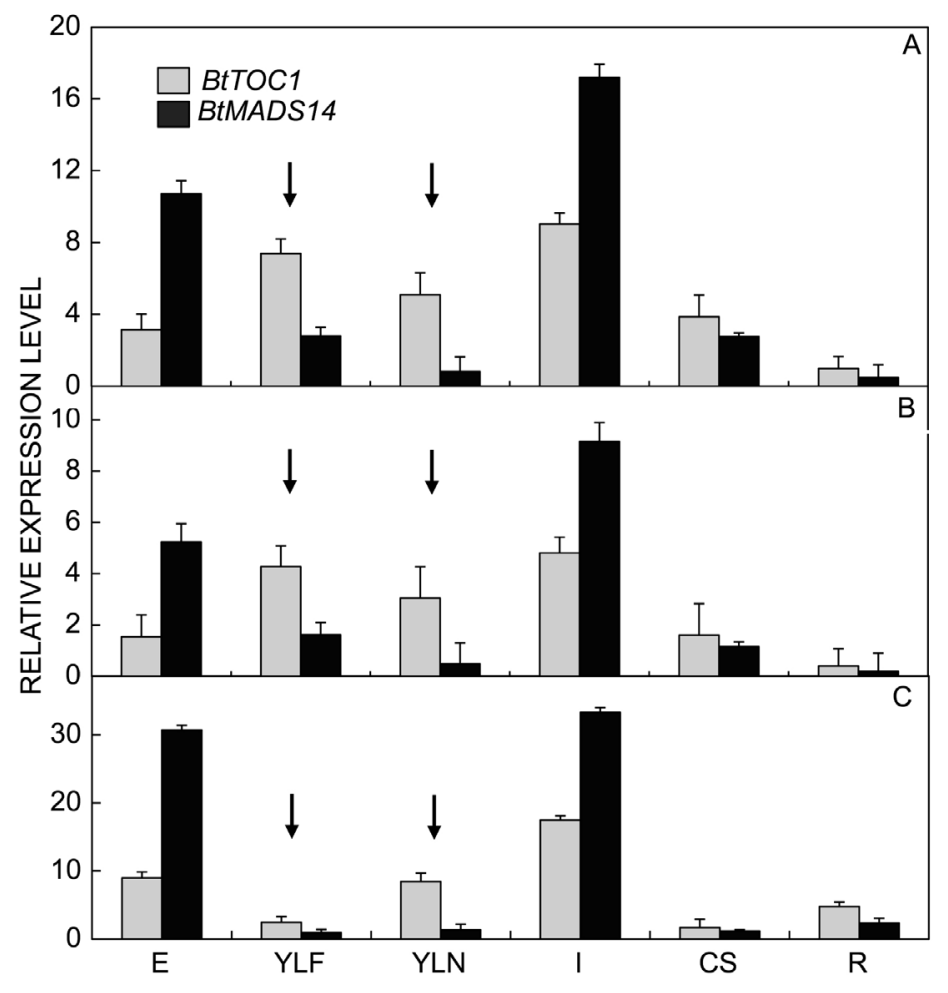

Fig. 4. Relative quantification of the floral inductive circadian clock gene BtTOC1 and the floral organ identity gene BtMADS14 using two most stable (eIF4 $\alpha$ and UBQ5) and one least stable (I8S) reference genes in different organs of Bambusa tulda. A relative fold change was calculated by the $2^{-\Delta \Delta C t}$ method using the expression data in rhizome as calibrator. Means of three biological replicates \pm SEs. Critical differences in expression pattern between young leaves from flowering culm (YLF) and young leaves from non-flowering culm (YLN) could be detected when eIF4 $\alpha$ and $U B Q 5$ were used for data normalization but not in case of $18 S$ (the arrow). Relative quantification of expressions of BtTOC1 and BtMADS14 genes using the one of the most stable reference genes eIF4a $(A)$ and $U B Q 5(B)$, or using the least stable reference gene $18 S(C)$. E - early staged inflorescence bud, I - internode, CS - culm sheath, $\mathrm{R}$ - root. 


\section{Discussion}

Bamboo is widely grown plant species across tropical and subtropical regions (Lobovikov et al. 2007). on this plant group and the only bamboo genome that has been sequenced is the temperate bamboo Phyllostachys edulis (Peng et al. 2013). The first step towards identification of stable reference genes in the tropical bamboos is to use real-time qPCR as a sensitive, quick, and reliable tool for gene expression analyses (Subburaj et al. 2017, Dutta et al. 2018, Santos et al. 2018). However, the accuracy of this method is heavily dependent on data normalization done by stably expressed reference genes. It is now well accepted that a single or a pair of reference genes that are useful for one species or experimental settings may not be equally useful for another species or even for the same species but under different experimental conditions (Morgante et al. 2011, De Andrade et al. 2017, Niu et al. 2017).

In this study, 10 candidate reference genes were selected and the stability of their expressions were investigated in 4 widely grown tropical bamboo species, 9 tissues, and 3 developmental stages by using 3 reliable computational tools geNorm (Vandesompele et al. 2002), NormFinder (Andersen et al. 2004), and RefFinder (Silver et al. 2006). When the stability of gene expressions was compared in three individual organs obtained from four different species of Bambusa, it was observed that an universal single reference gene could not normalize data in all these tissue stages and species. For instance, $e I F 4 \alpha$ and $C A C$ were most suitable in the case of leaf and internode tissues across four different bamboo species, but not for rhizomes (Fig. $2 A, B, C$; Table 3 Suppl.). Only limited studies have been conducted to identify reference genes that are stable across taxonomic ranks such as species (Iskandar et al. 2004, Morgante et al. 2011), varieties, and genotypes (Saha and Blumwald 2014, Pabuayon et al. 2016).

Analyses conducted in different organs across four bamboo species suggest that gene expression stability can also be seriously affected by organs. All the three computational tools identified $e I F 4 \alpha$ as the most stable reference gene across selected organs of $B$. tulda

\section{References}

Andersen, C.L., Jensen, J.L., Ørntoft, T.F.: Normalization of real-time quantitative reverse transcription-PCR data: a model-based variance estimation approach to identify genes suited for normalization, applied to bladder and colon cancer data sets. - Cancer Res. 64: 5245-5250, 2004.

Biswas, P., Chakraborty, S., Dutta, S., Pal, A., Das, M.: Bamboo flowering from the perspective of comparative genomics and transcriptomics. - Front. Plant Sci. 7: 1900, 2016.

Bustin, S., Benes, V., Nolan, T., Pfaffl, M.W.: Quantitative realtime RT-PCR - a perspective. - J. mol. Endocrinol. 34: 597-
(Fig. 2D, Table 3 Suppl.). It is contrary to the findings in $P$. edulis, where $N T B$ and $C Y P$ were identified as the most stable reference genes across different tissues (Fan et al. 2013). One possible explanation for such deviation might be the inclusion of additional organs such as rhizome, culm sheath, and different types of leaves used in the present study but not in the previous one (Fan et al. 2013). The $e I F 4 \alpha$ and $U B Q 5$ have been successfully used for normalization of gene expression data in other species as well. For instance, eIF4 $\alpha$ has been used across different tissues of alfalfa (Guerriero et al. 2014) and $U B Q 5$ for different developmental stages of rice (Lin et al. 2016). In addition to organs, also with respect to the developmental stages, this study is much more exhaustive than the previous one. Indeed, the expression stability of the reference genes were affected by developmental stages of the individual organs analyzed. However, a higher variation of the expression stability of a single reference gene was observed across multiple organs than across developmental stages. This heterogeneity in expression stability is confirmatory to the requirement of a higher number of reference genes for data normalization in the case of organ specific analysis. The validity of the selected reference genes was confirmed by studying the relative expression profile of BtTOC1 and BtMADS14 in different vegetative and floral tissues. Indeed, an expected flower inductive pattern in YLF and YLN was observed for both BtTOC1 and BtMADS14 genes when $e I F 4 \alpha$ and $U B Q 5$ were used to normalize the gene expression data, whereas it was reversed when $18 \mathrm{~S}$ was used. The TOC1 is an important circadian clock gene known to be involved in the induction of flowering in plants, and its role in the photoperiodic induction of bamboo flowering has also been studied (Dutta et al. 2018). The MADS14 is a floral inductive transcription factor, which determines the identity of floral meristem (Wu et al. 2017). Nevertheless, future studies are required to study the impacts of additional factors, such as seasons, on the expression stability of selected genes for normalization (Kim et al. 2015).

$601,2005$.

Chen, X., Mao, Y., Huang, S., Ni, J., Lu, W., Hou, J., Wang, Y., Zhao, W., Li, M., Wang, Q., Wu, L.: Selection of suitable reference genes for quantitative real-time PCR in Sapium sebiferum. - Front Plant Sci. 8:637, 2017.

Clark, L.G., Londoño, X., Ruiz-Sanchez, E: Bamboo taxonomy and habitat. - In: Liese W., Köhl M. (ed.): Bamboo. Tropical Forestry. Vol. 10. Pp. 1-30. Springer, Cham 2015.

Clark, L.G., Judziewicz, E.J., Tyrrel, C.D.L: Aulonemia ximenae (Poaceae: Bambusoideae), a new northern Andean species with fimbriate sheath margin. - Bamboo Sci. Cult. 
20: 1-6, 2007.

Clark, L.G., Zhang, W., Wendel, J.F.: A phylogeny of the grass family (Poaceae) based on $n d h F$ sequence data. - Syst. Bot. 20: 436-460, 1995.

Das, M., Bhattacharya, S., Singh, P., Filgueiras, T.S., Pal, A.: Bamboo taxonomy and diversity in the era of molecular markers. - Adv. bot. Res. 47: 225-268, 2008.

Das, M., Haberer, G., Panda, A., Das Laha, S., Ghosh, T.C., Schäffner, A.R.: Expression pattern similarities support the prediction of orthologs retaining common functions after gene duplication events. - Plant Physiol. 171: 2343-2357, 2016.

Das, M., Pal, A.: In vitro regeneration of Bambusa balcooa Roxb.: Factors affecting changes of morphogenetic competence in the axillary buds. - Plant Cell Tissue Organ Cult. 81: 109-112, 2005.

Das, M., Reichman, J.R., Haberer, G., Welzl, G., Aceituno, F.F., Mader, M.T., Watrud, L.S., Pfleeger, T.G., Gutiérrez, R.A., Schäffner, A.R., Olszyk, D.M.: A composite transcriptional signature differentiates responses towards closely related herbicides in Arabidopsis thaliana and Brassica napus. - Plant mol. Biol. 72: 545-56, 2010.

De Andrade, L.M., Dos Santos Brito, M., Fávero Peixoto, R., Jr., Marchiori, P.E.R., Nóbile, P.M., Martins, A.P.B., Ribeiro, R.V., Creste, S.: Reference genes for normalization of qPCR assays in sugarcane plants under water deficit. Plant Methods 13: 28-37, 2017.

Dutta, S., Biswas, P., Chakraborty, S., Mitra, D., Pal, A., Das, M.: Identification, characterization and gene expression analyses of important flowering genes related to photoperiodic pathway in bamboo. - BMC Genomics 19: 190, 2018.

Fan, C., Ma, J., Guo, Q., Li, X., Wang, H., Lu, M.: Selection of reference genes for quantitative real-time PCR in bamboo (Phyllostachys edulis). - PLoS ONE 8: e56573, 2013.

Fedick, A., Su, J., Jalas, C., Treff, N.R.: High-throughput realtime PCR-based genotyping without DNA purification. BMC Res Notes 5: 573, 2012.

Gielis, J., Everaert, I., De Loose, M.: Genetic variability and relationships in Phyllostachys using random amplified polymorphic DNA. -In: Chapman, G.P. (ed): TheBbamboos. Pp. 107-124. Academic Press, London 1997.

Ginzinger, D.G.: Gene quantification using real-time quantitative PCR: an emerging technology hits the mainstream. - Exp. Hematol. 30: 503-512, 2002.

Guerriero, G., Legay, S., Hausman, J.F.: Alfalfa cellulose synthase gene expression under abiotic stress: a Hitchhiker's guide to RT-qPCR normalization. - PLoS ONE 9: e103808, 2014.

Guo, J., Ling, H., Wu, Q., Xu, L., Que, Y.: The choice of reference genes for assessing gene expression in sugarcane under salinity and drought stresses. - Sci. Rep. 4: 7042, 2014.

Hu, Y., Chen, H., Luo, C., Dong, L., Zhang, S., He, X., Huang, G.: Selection of reference genes for real-time quantitative PCR studies of kumquat in various tissues and under abiotic stress. - Sci. Hort. 174: 207-216, 2014.

Iskandar, H.M., Simpson, R.S., Casu, R.E., Bonnett, G.D., Maclean, D.J, Manners, J.M.: Comparison of reference genes for quantitative real-time polymerase chain reaction analysis of gene expression in sugarcane. - Plant mol. Biol. Rep. 22: 325-337, 2004.

Jain, M., Nijhawan, A., Tyagi, A.K., Khurana, J.P.: Validation of housekeeping genes as internal control for studying gene expression in rice by quantitative real-time PCR. - Biochem. biophys. Res. Commun. 345: 646-51, 2006.

Janská, A., Hodek, J., Svoboda, P., Zámečník, J., Prášil, I.T., Vlasáková, E., Milella, L., Ovesná, J.: The choice of reference gene set for assessing gene expression in barley (Hordeum vulgare L.) under low temperature and drought stress. - Mol. Genet. Genomics 288: 639-49, 2013.

Janzen, D.H.: Why bamboos wait so long to flower. - Annu. Rev. Ecol. Syst. 7: 347-391, 1976.

Jian, B., Liu, B., Bi, Y., Hou, W., Wu, C., Han, T.: Validation of internal control for gene expression study in soybean by quantitative real-time PCR. - BMC mol. Biol. 9: 59, 2008.

Kellogg, E.A.: Flowering plants, monocots, Poaceae. In: Kubitzki K. (ed.): The Families and Genera of Vascular Plants Vol. XIII. Pp. 1-496. Springer, Cham 2015.

Kim, H.Y., Saha, P., Farcuh, M., Li, B., Sadka, A., Blumwald, E.: RNA-seq analysis of spatio-temporal gene expression patterns during fruit development revealed reference genes for transcript normalization in plums. - Plant mol. Biol. Rep. 33: 1634-1649, 2015.

Li, M.Y., Wang, F., Jiang, Q., Wang, G.L., Tian, C., Xiong, A.S.: Validation and comparison of reference genes for qPCR normalization of celery (Apium graveolens) at different development stages. - Front. Plant Sci. 7: 313, 2016.

Lin, F., Manisseri, C., Fagerström, A., Peck, ML., VegaSánchez, ME., William,s B., Chiniquy, DM., Saha, P., Pattathil, S., Conlin, B., Zhu, L., Hahn, MG., Willats, WG., Scheller, HV., Ronald, PC., Bartley, LE.: Cell wall composition and candidate biosynthesis gene expression during rice development. - Plant Cell Physiol. 57: 20582075, 2016.

Ling, H., Wu, Q., Guo, J., Xu, L., Que, Y.: Comprehensive selection of reference genes for gene expression normalization in sugarcane by real time quantitative RTPCR. - Plos ONE 9: e97469, 2014.

Livak, K.J., Schmittgen, T.D.: Analysis of relative gene expression data using real-time quantitative PCR and the $2^{-\Delta \Delta C T}$ method. - Methods 25: 402-08, 2001.

Lobovikov, M., Paudel, S., Piazza, M., Wu, H.R.: World Bamboo Resources: a Thematic Study Prepared in the Framework of the Global Forest Resources Assessment. Food and Agriculture Organization of the United Nations, Rome 2007.

Marchesini, V.A., Sala, O.E., Austin, A.T.: Ecological consequences of a massive flowering event of bamboo (Chusqueaculeou) in a temperate forest of Patagonia, Argentina. - J. veg. Sci. 20: 424-432, 2009.

Morgante, C.V., Guimarães, P.M., Martins, A.C.Q., Araújo, A.C.G., Leal-Bertioli, S.C.M., Bertioli, D.J., Brasileiro, A.C.M.: Reference genes for quantitative reverse transcription-polymerase chain reaction expression studies in wild and cultivated peanut. - BMC Res. Notes 4: 339, 2011.

Niu, X., Chen, M., Huang, X., Chen, H., Tao, A., Xu, J., Qi, J.: Reference gene selection for qRT-PCR normalization analysis in kenaf (Hibiscus cannabinus L.) under abiotic stress and hormonal stimuli. - Front. Plant Sci. 8: 771, 2017.

Owen, A.: Bamboo!! Improving island economy and resilience with Guam college students. - J. Marine Island Cult. 4: 65$75,2015$.

Pabuayon, I.M., Yamamoto, N., Trinidad, J.L., Longkumer, T., 
Raorane, M.L., Kohli, A.: Reference genes for accurate gene expression analyses across different tissues, developmental stages and genotypes in rice for drought tolerance. - Rice 9: 32, 2016.

Peng, Z., Lu, Y., Li, L., Zhao, Q., Feng, Q., Gao, Z., Lu, H., Hu, T., Yao, N., Liu, K., Li, Y., Fan, D., Guo, Y., Li, W., Lu, Y., Weng, Q., Zhou, C., Zhang, L., Huang, T., Zhao, Y., Zhu, C., Liu, X., Yang, X., Wang, T., Miao, K., Zhuang, C., Cao, X., Tang, W., Liu, G., Liu, Y., Chen, J., Liu, Z., Yuan, L., Liu, Z., Huang, X., Lu, T., Fei, B., Ning, Z., Han, B., Jiang, Z.: The draft genome of the fast-growing non-timber forest species moso bamboo (Phyllostachys heterocycla). Nat. Genet. 45: 456-461, 2013.

Ramanayake, S.M.S.D., Meemaduma, V.N., Weerawardene, T.E.: In vitro shoot proliferation and enhancement of rooting for the large-scale propagation of yellow bamboo (Bambusa vulgaris 'Striata') - Sci. Hort. 110: 109-113, 2006.

Reddy, D.S., Bhatnagar-Mathur, P., Reddy, P.S., Sri Cindhuri, K., Sivaji Ganesh A, Sharma, K.K.: Identification and validation of reference genes and their impact on normalized gene expression studies across cultivated and wild Cicer species. - PLoS ONE 11: e0148451, 2016.

Saha, P., Blumwald, E.: Assessing reference genes for accurate transcript normalization using quantitative real-time PCR in pearl millet [Pennisetum glaucum (L.) R. Br.]. - PLoS ONE 9: e106308, 2014.

Santos, FICD., Marini, N., Santos, RSD., Hoffman, BSF., Alves-Ferreira, M., De Oliveira, AC.: Selection and testing of reference genes for accurate RT-qPCR in rice seedlings under iron toxicity. - PLoS ONE 13: e0193418, 2018.

Sertse, D., Disasa, T., Bekele, K., Alebachew, M., Kebede, Y., Eshete, N., Eshetu, S.: Mass flowering and death of bamboo: a potential threat to biodiversity and livelihoods in Ethiopia. - J. biol. environ. Sci. 1: 16-25, 2011.

Silva, R.L.O., Silva, M.D., Ferreira, Neto, J.R.C., Nardi, C.H., Chabregas, S.M., Burnsquist, W.L., Kahl, S., BenkoIseppon, A.M., Kido, E.A.: Validation of novel reference genes for reverse transcription quantitative real-time PCR in drought stressed sugarcane. - Sci. World J. 2014: 1-12, 2014.

Silver, N., Best, S., Jiang, J., Thein, S.L.: Selection of housekeeping genes for gene expression studies in human reticulocytes using real-time PCR. - BMC mol. Biol. 7: 33, 2006.

Sood, Y.V., Pande, P.C., Tyagi, S., Payra, I., Kulkarni, N., Kulkarni, A.G.: Quality improvement of paper from bamboo and hardwood furnish through fiber fractionation. J. sci. indian Res. 64: 299-305, 2005.

Subburaj, S., Zhu, D., Li, X., Hu, Y., Yan, Y.: Molecular characterization and expression profiling of Brachypodium distachyon L. cystatin genes reveal high evolutionary conservation and functional divergence in response to abiotic stress. - Front. Plant Sci. 8: 743, 2017.

Vandesompele, J., Preter, K.D., Pattyn, F., Poppe, B., Roy, N.V., Paepe, A.D., Speleman, F.: Accurate normalization of real-time quantitative RT-PCR data by geometric averaging of multiple internal control genes. - Genome Biol 3: 0034.10034.11, 2002.

Wai, N.N., Nanko, H., Murakami, K.: A morphological study on the behavior of bamboo pulp fibers in the beating process. - Wood Sci. Technol. 19: 211-222, 1985.

Wan, H., Yuan, W., Ruan, M., Ye, Q., Wang, R., Li, Z., Zhou, G., Yao, Z., Zhao, J., Liu, S., Yang, Y.: Identification of reference genes for reverse transcription quantitative realtime PCR normalization in pepper (Capsicum annuum L.). Biochem. biophys. Res. Commun. 416: 24-30, 2011.

Wang, M.L., Li, Q.H., Xin, H.H., Chen, X., Zhu, X.J., Li, X.H.: Reliable reference genes for normalization of gene expression data in tea plants (Camellia sinensis) exposed to metal stresses. - PLoS ONE 12: e0175863, 2017.

Wu, F., Shi, X., Lin, X., Liu, Y., Chong, K., Theissen, G., Meng, Z.: The ABCs of flower development: mutational analysis of $A P 1 / F U L$-like genes in rice provides evidence for a homeotic (A)-function in grasses. - Plant J. 89: 310324, 2017.

Yuan, J.L., Yue, J.J., Gu, X.P., Lin, C.S.: Flowering of woody bamboo in tissue culture systems. - Front. Plant Sci. 8: 1589, 2017.

Zhang, W.: Phylogeny of the grass family (Poaceae) from $\mathrm{rpl}$ 16 intron sequence data. - Mol. Phylogenetics Evol. 15: 135-146, 2000. 